\title{
Retention of ${ }^{226} \mathrm{Ra}$ by barite:
}

\section{the role of internal porosity}

3 Juliane Weber $^{1 *}$, Juri Barthel ${ }^{2,3}$, Martina Klinkenberg ${ }^{l}$, Dirk Bosbach ${ }^{1}$, Maximilian Kruth ${ }^{2,3}$,

Felix Brandt ${ }^{1}$

5

6

7

8

\section{Abstract}

12 The role of internal macropores and nano-scale pores for the uptake of ${ }^{226} \mathrm{Ra}$ into barite was studied via scanning and transmission electron microscopy as well as focused ion beam methods. A temporal evolution of the internal microstructure and the Ra distribution was observed on samples taken from long-term Ra uptake experiments. The results of this study clearly show a significant impact of the presence of Ra leading to a complete reconstruction of the internal barite microstructure, whereas the microstructure of Ra-free reference samples 
of macropores and a layered structure of nano-scale pores which, in the presence of Ra, coalesced in favor of larger pores during the experiment. A clear relationship between the Ra uptake and the internal porosity was observed by high-resolution STEM-EDX mappings.

Starting from strongly enhanced Ra concentrations in the solid in the vicinity of the pores, Ra is temporarily inhomogeneously distributed within the barite particles. At later stages of the long-term experiment the Ra distribution becomes homogenous while nano-scale and macroscale pores disappear. In conclusion, the uptake of Ra into barite takes place by a special case of dissolution/reprecipitation from the inside of the particle to the outside. waste management, electron microscopy, elemental mapping, FIB-SEM tomography

\section{Introduction}

The long-term fate of ${ }^{226} \mathrm{Ra}$ is of great environmental relevance due to its ubiquitous occurrence in the oil, gas and coal exploration and extraction and the resulting naturally occurring radioactive materials (NORM) (Varley et al., 2016; Attalah et al., 2015; Kondash et al., 2014; Rosenberg et al., 2014). Ra is one of the most important primary sources of elevated radioactivity created by industrial activity, energy production and mining. Coprecipitation and solid solution formation of Ra-phases with sparingly soluble sulfates, especially barite, leads to unwanted radioactive scale formation (Kondash et al., 2014; Al Attar et al., 2016).

40 Recently, the role of solid solution formation as an essential process for the remediation of contaminants was discussed (e.g. review of Prieto et al., 2016). In the case of Ra, the same mechanism which leads to unwanted radioactive scales is also applied to reduce the levels of

$43 \mathrm{Ra}$ in the environment to legal standards, e.g. for the NORM removal from hydraulic 
fracturing fluids. Therefore, the formation of the $(\mathrm{Ba}, \mathrm{Ra}) \mathrm{SO}_{4}$ solid solution from high supersaturation has been intensively studied with respect to technical processes for the $\mathrm{Ra}$ removal (e.g. Stoica et al., 1998; Chalupnik et al., 2008). A recent review on the treatment of water contaminated with $\mathrm{Ra}$ poses the question of the long-term stability of the $(\mathrm{Ba}, \mathrm{Ra}) \mathrm{SO}_{4}$ when disposed in lakes (IAEA, 2014). This open question still seems to hinder the application of $(\mathrm{Ba}, \mathrm{Ra}) \mathrm{SO}_{4}$ co-precipitation for processing contaminated water.

$\mathrm{Ra}$ uptake at close-to-equilibrium conditions refers to the long-term behavior of $\mathrm{Ra}$ in the environment (Zhang et al., 2014; Rosenberg et al., 2011a, b). The special case of the contact between pre-existing barite and $\mathrm{Ra}$ in solution and their possible re-equilibration to a $(\mathrm{Ba}, \mathrm{Ra}) \mathrm{SO}_{4}$ solid solution at close-to-equilibrium conditions has been a question of interest in several recent publications (e.g. Grandia et al., 2008; Bruno et al., 2007; Curti et al., 2010; Brandt et al., 2015; Torapava et al., 2014), because ${ }^{226} \mathrm{Ra}$ is a key radionuclide in safety assessments of deep geological waste repositories for spent nuclear fuel. $(\mathrm{Ba}, \mathrm{Ra}) \mathrm{SO}_{4}$ was recognized as possibly solubility limiting phase for $\mathrm{Ra}$ in the context of direct disposal of spent nuclear fuel. Based on thermodynamic considerations, uptake into pre-existing barite is predicted to be the main scavenger of Ra in several scenarios (Vinograd et al., 2013).

60 Recent experimental results demonstrated a complete recrystallization of pre-existing barite in the presence of $\mathrm{Ra}$ in time-scales of several hundred days (Bosbach et al., 2010; Curti et al., 2010). A detailed experimental study presenting repetitive long-term batchrecrystallization experiments was carried out by Brandt et al. (2015). This study provides an in-depth analysis of the solution chemistry, modelling of kinetics and thermodynamic data of the Ra uptake into barite based on a number of experiments conducted under carefully selected experimental parameters (solid/liquid ratio, grain size, and specific surface area). experiments is discussed in Brandt et al. (2015) and can be summarized by the following 

three stages describing three different kinetic regions (Fig. 1), (1) slow initial decrease of the Ra concentration; (2) a faster decrease to a minimum Ra concentration below the predicted thermodynamic equilibrium (dashed line in Fig. 1) and (3) approach to thermodynamic equilibrium. The Ra-concentration in the solution is decreased by about $99.99 \%$ of its initial value (Brandt et al., 2015).

Due to different onset times of the fast Ra decrease in solution, the concentration plateau was reached during a time interval of 600 to 1100 days (Brandt et al., 2015).

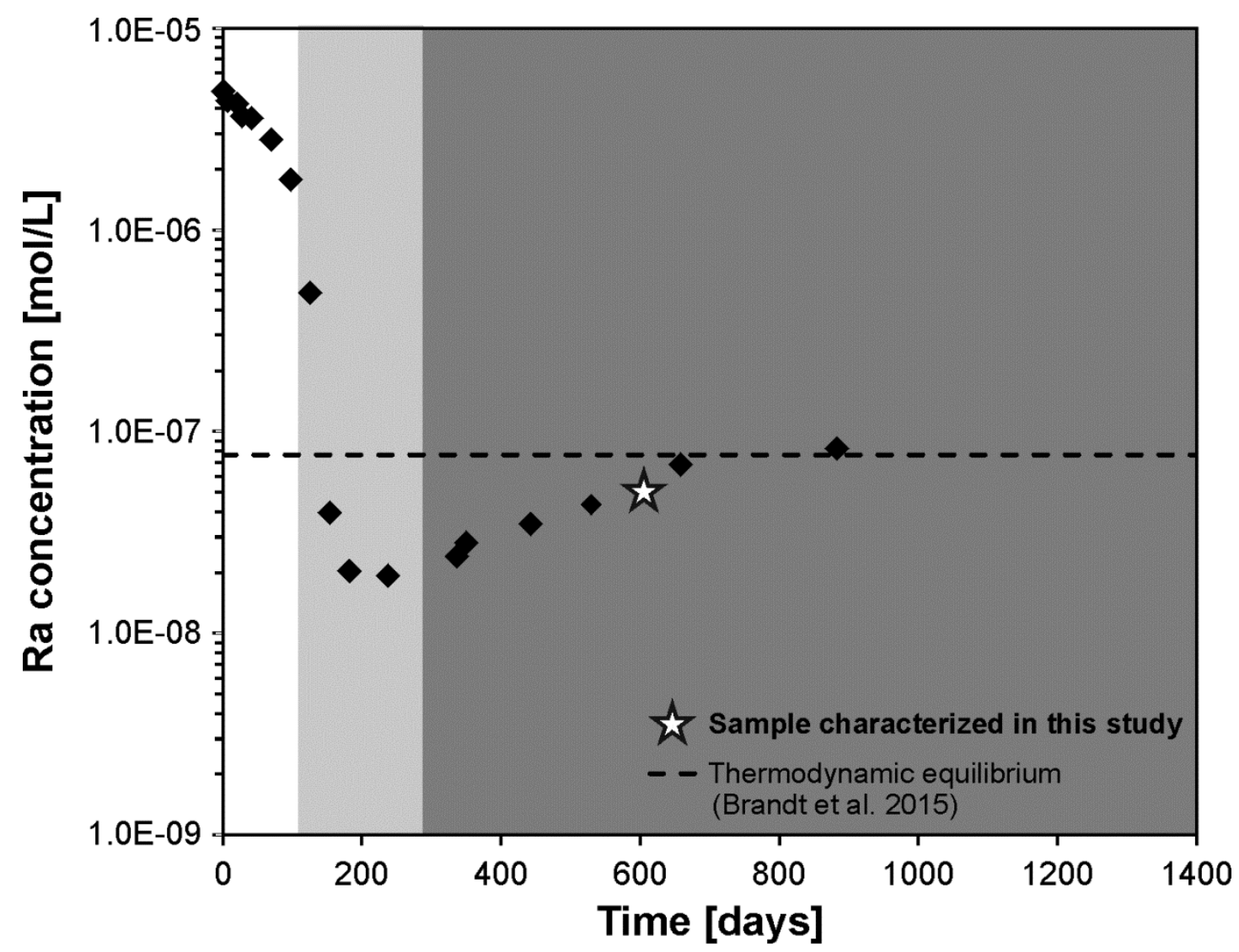

Fig. 1. Temporal evolution of the aqueous Ra concentration during a Ra uptake experiment as discussed by Brandt et al. (2015). The white area refers to stage 1, the light grey area to stage 2 and the dark grey area to stage 3 of the Ra-uptake. A sample from this experiment ( $\star$ ) was taken for comparison with an experiment carried out in the present study. 
83 In order to gain fundamental insights into the uptake process, microscopic studies were conducted analyzing the barite morphology before and after the Ra uptake in comparison to Ra-free reference experiments (Klinkenberg et al., 2014). In this previous work, only very little changes of the outer shape and size of the barite particles were observed, leading to the conclusion that the uptake of Ra must be related to internal processes. The spatial resolution of the ToF-SIMS analysis provided in the same study allowed for the distinction between a surface layer and the Ra uptake into the crystal volume (Klinkenberg et al., 2014). Ra was clearly identified within the barite crystal volume. However, the pathways enabling the Ra uptake into barite and the temporal evolution of the Ra distribution within the newly formed solid-solution remained unclear. The studies of Brandt et al. (2015) and Klinkenberg et al. (2014) are forming the basis for the here presented results. As the study of Brandt et al. (2015) provides the complete and detailed description of the evolution of the Raconcentration, the solution chemistry is only briefly covered here.

At ambient conditions, a replacement of pure barite by $(\mathrm{Ba}, \mathrm{Ra}) \mathrm{SO}_{4}$ via solid state diffusion starting from the particle surface would be too slow for a complete exchange considering diffusion rates in minerals depicted e.g. in Zhang et al. (2008 and 2010). An alternative mechanism could be dissolution-reprecipitation, which has been recently studied extensively (e.g. reviews of Ruiz-Agudo et al., 2014; Altree-Williams et al., 2015). Despite the wide recognition of internal mineral phase exchange due to pseudomorphic replacement (e.g. RuizAgudo et al., 2014; Altree-Williams et al., 2016; Putnis \& Putnis, 2007; Hellmann et al., 2015), the underlying mechanisms remains not fully understood. The current understanding is that during a dissolution-reprecipitation process, a mineral phase $\mathrm{AC}$ consisting of a cation $\mathrm{A}$ and an anion $\mathrm{C}$ re-equilibrates due to a disequilibrium with another cation $\mathrm{B}$ in solution. This leads to the subsequent precipitation of the less soluble solid solution (A,B)C. For a complete 
107 exchange, the interface between the solid and the aqueous solution needs to stay connected to 108 the bulk fluid. Therefore, the newly precipitated phase needs to be porous.

109 The replacement of a parent mineral phase by a product phase is accompanied by changes 110 in the overall porosity. Two main factors have an effect on this change in porosity. The first

111 factor is the difference in the molar volume between the parent and the product phase. In 112 addition, the second factor influencing the change in porosity is the solubility of the two 113 phases (Putnis \& Austrheim, 2013; Ruiz-Agudo et al., 2014). The solubility is determined by

114 the grain size, fluid composition, temperature and pressure among other factors and will 115 change during the replacement process. Large differences in solubility between parent phase 116 (more soluble) and product phase (less soluble) might results in parent material loss during 117 the reaction leading to an increased pore space in the product phase. Also, an increase in 118 molar volume during replacement from the parent phase to the product phase can still result 119 in a higher porosity. This was observed e.g. for the replacement of leucite by analcime 120 (Putnis et al., 2007) or magnetite by pyrite (Qian et al., 2010). Furthermore, the strain which 121 is related to high volume change reaction can induce fracturing which provides new pathways 122 for fluid infiltration.

123 The change in porosity was defined by Pollock et al. (2011) not only regarding the molar 124 volume but also the relative solubilities (Eq. 1):

$$
\begin{aligned}
& V \\
& =100 \times\left(\frac{n_{p} V_{m, p}-n_{d} V_{m, d}}{n_{d} V_{m, d}}\right)
\end{aligned}
$$

125 Where $n_{d}$ and $n_{p}$ are the number of moles of the parent dissolved and the product 126 precipitated and $\mathrm{V}_{\mathrm{m}, \mathrm{d}}$ and $\mathrm{V}_{\mathrm{m}, \mathrm{p}}$ are the molar volumes of the dissolving and precipitating 127 phase respectively. For further references Altree-Williams et al. (2015) provide an extensive 128 review on textural changes during mineral replacement by dissolution and reprecipitation.

129 The change in molar volume for the exchange of barite by a $\mathrm{Ba}_{\mathrm{x}} \mathrm{Ra}_{1-\mathrm{x}} \mathrm{SO}_{4}$ solid solution can 
130 be estimated considering the change in molar volume by a complete replacement of barite by

131 pure $\mathrm{RaSO}_{4}$ first. Using equation (1), the change in molar volume can be calculated using the molar volumes of barite $\left(47.95 \mathrm{~cm}^{3} / \mathrm{mol}\right)$ based on Hanor (2000) and a molar volume of pure

$133 \mathrm{RaSO}_{4}$ of $55.87 \mathrm{~cm}^{3} / \mathrm{mol}$ (Weigel \& Trinkl, 1968). The precipitated and dissolved moles are

134 set to one assuming complete replacement.

$$
\Delta V=\left(\frac{1 \times 55.87-1 \times 47.95}{1 \times 55.87}\right)=14.17 \%
$$

135 Accordingly, the change in molar volume for the complete replacement of barite by pure $136 \mathrm{RaSO}_{4}$ would be $14.17 \%$.

137 The solubility of barite is well studied over a range of temperatures and for this calculation, 138 the solubility at ambient conditions provided by Blount (1977) of $\log \mathrm{K}_{\mathrm{BaSO} 4}$ of -9.97 is used.

139 For $\mathrm{RaSO}_{4}$, the solubility constant implemented in the Nagra-PSI database (Thoenen et al., 140 2014) is $\log \mathrm{K}_{\mathrm{RasO} 4}=-10.26$ as obtained by Langmuir and Riese (1985). Therefore, the 141 difference in solubility between barite and $\mathrm{RaSO}_{4}$ is less than $2.8 \%$.

142 A complete exchange of barite by radiobarite with a sufficient amount of Ra in solution would be expected to be accompanied by considerable microstructural changes. In contrast,

144 the complete exchange with the relatively small amount of Ra provided in the experiments of 145 Brandt et al. (2015) would be expected to lead only to minor microstructural changes.

146 The replacement process of mineral phase AC by a $(\mathrm{A}, \mathrm{B}) \mathrm{C}$ solid solution is based on the 147 thermodynamic principle of energy minimization, yet this does not completely explain the 148 kinetic driving forces. Only very little information is so far available about the kinetic driving 149 forces controlling the mineral recrystallization and contaminant uptake relevant to the 150 environment. Based on a detailed study of calcite, Ostwald ripening driven by surface energy 151 minimization has been proposed as one important mechanism for recrystallization (Heberling 152 et al., 2016). In a recent review about mineral recrystallization at low temperatures $\left(<100{ }^{\circ} \mathrm{C}\right)$ 
153 the importance of applying high resolution microscopy techniques has been emphasized to

154 gain further insights into the molecular scale mechanism of stable mineral recrystallization

155 (Gorski et al., 2016).

156 It is well known that natural barites often contain fluid inclusions entrapped during crystal

157 growth (Böhlke \& Irwin, 1992; Jamieson et al., 2016). Weber et al. (2016) characterized the

158 fluid inclusions existing in barite which had earlier been used in the Ra uptake experiments of

159 Curti et al. (2010), Klinkenberg et al. (2014) and Brandt et al. (2015). Nano-scale fluid

160 inclusions filled with water and $\mathrm{NaCl}$ have been found to be arranged in layers by applying a

161 complimentary approach of transmission electron microscopy (TEM) methods and atom

162 probe tomography (ATP).

163 Here, we present a detailed electron microscopy and focused ion beam study addressing the 164 temporal evolution of $\mathrm{Ra}$ uptake by pre-existing barite with a focus on the internal 165 microstructure and the distribution of Ra during the different uptake stages. By applying 166 TEM techniques in 2D in combination with a focused ion beam and scanning electron 167 microscopy (FIB-SEM) analysis in three spatial dimensions on samples taken at different 168 times of the Ra uptake, we provide essentially a four-dimensional description of the uptake 169 process.

$171 \quad 2 . \quad$ Materials and Methods

\section{$172 \quad 2.1 \quad$ Barite samples from batch-type Ra uptake experiments}

173 A batch type experiment was carried out with the aim of preparing samples for a detailed 174 microscopic study of the temporal evolution of the internal microstructure of barite during Ra 175 uptake. The setup of the batch-type recrystallization experiment was identical to that 176 described in Klinkenberg et al. (2014). During the experiment, a synthetic high-purity barite 177 (XR-HR-10) from Sachtleben Chemie ${ }^{\circledR}$ GmbH (SL barite) was put into contact with a 
178 Ra-containing solution. The initial experimental conditions were a solid to liquid ratio of

$1790.5 \mathrm{~g} / \mathrm{L}$ and a ${ }^{226} \mathrm{Ra}$ concentration in solution of $5 \cdot 10^{-6} \mathrm{~mol} / \mathrm{L}$. The concentration of ${ }^{226} \mathrm{Ra}$ in

180 solution was analyzed using Gamma-Spectroscopy after filtering using a 10,000 Da Advantec

181 ultrafilter.

182 Parallel to the sampling of the aqueous solution, solid samples were taken from each stage

183 of the experiment and prepared on a Si-wafer after washing with iso-propanol for electron

184 microscopy according to the procedure described in Klinkenberg et al. (2014). For 185 comparison, a barite sample taken after 602 days from the experiment presented as SL

$1860.5 \mathrm{~g} / \mathrm{L}$ in Brandt et al. (2015) was analyzed as well (Fig. 1). Reference experiments without

187 Ra were carried out to separate the possible effects of recrystallization with and without Ra.

$189 \quad 2.2 \quad$ Characterization of the solids

\section{$190 \quad$ 2.2.1 FIB cross-section preparation and image analysis}

191 Preparation procedures are described in detail in Weber et al. (2016) and in the references

192 provided therein. Cross-sections along the longest particle axis were prepared by applying a

193 variety of FIB instruments. Ra-containing samples were prepared in a Zeiss NVision40 cross

194 beam workstation (Carl Zeiss AG, Germany) located in a controlled area, whereas Ra-free

195 reference samples were prepared in two different but equivalent instruments, a FEI Helios

196 NanoLab 460F1 (Kruth et al., 2016) or a FEI Helios Nanolab 400S (Meertens et al., 2016;

197 FEI Company, The Netherlands).

198 The macropores within the barite samples were evaluated by the analysis of SEM images

199 taken from FIB cross-sections. The areas comprising the complete particle and the areas

200 corresponding to pores were separated and extracted by means of a contrast analysis (ImageJ)

201 of the SEM images (Fig. 2). The area based macroporosity was calculated from the ratio of 
the total particle and the macropore areas. A number of at least ten FIB cross-sections were prepared for this purpose and analyzed from each individual sample listed in Table 1.
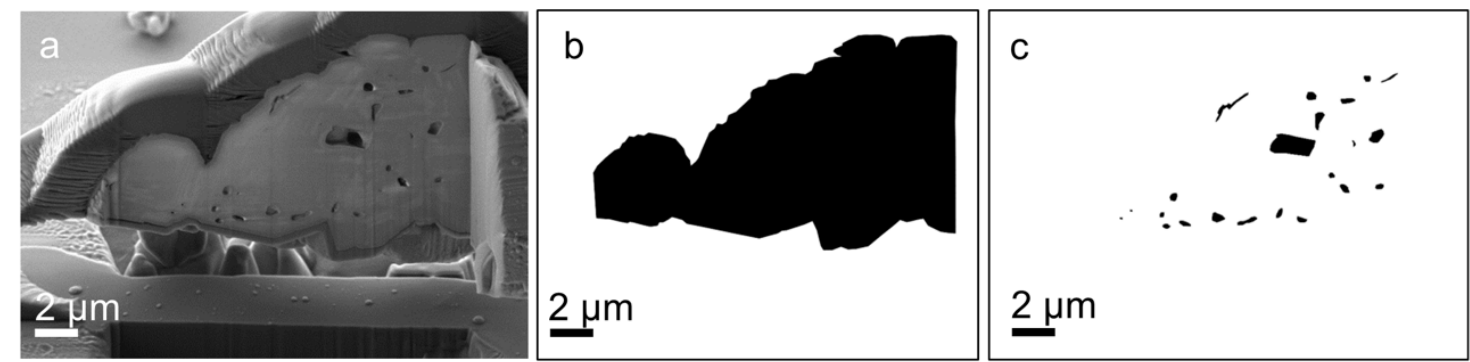

Fig. 2. Image analysis for the determination of the area based macroporosity: (a) SEM image of a barite particle FIB section, (b) extracted area of the barite particle, (c) extracted area of macropores

207

\subsubsection{FIB-SEM tomography}

209

FIB-SEM tomography with the slice \& view technique (Holzer et al., 2004) was performed using a FEI Helios NanoLab 460F1 FIB-SEM instrument (FEI Company, The Netherlands;

211 Kruth et al., 2016) to obtain the 3D visualization of the macropore distribution within the

212 initial SL barite prior the addition of Ra. Slices of several barite particles were cut parallel to

213 the longest particle axis and studied by SEM using secondary electron (SE) images. A

$21430 \mathrm{kV} / 2.5 \mathrm{nA} \mathrm{Ga}$ ion beam was applied to cut two trenches on both sides of the particle and

215 then a third trench from the front of the area of interest to expose the first segment of the

216 slice-and-view section.

217 Tomographic data sets were acquired by sequential cutting of in total 734 slices of 218 approximately $20 \mathrm{~nm}$ thickness with a $2.5 \mathrm{nA}$ ion beam and subsequent SEM. Each cross219 section was imaged in mirror detection (MD) mode as well as by a through-the-lens backscattered (TLD-BS) detector using a $2 \mathrm{kV} / 0.4 \mathrm{nA}$ electron beam with a scan step size of $7.68 \mathrm{~nm}$. The recorded SEM images were combined as a stack in a single three-dimensional volume by the tools available in the AVIZO 9.0.0 software package (FEI Company, The 
223 Netherlands). Subsequently, the segmentation of the pore space was performed with the same software package.

225

\subsubsection{TEM Sample preparation by focused ion beam (FIB)}

227 TEM lamellae with a thickness below $100 \mathrm{~nm}$ were cut from the barite particles using a 228 focused ${ }^{69} \mathrm{Ga}^{+}$ion beam (FIB) instrument. The same variety of instruments as used for FIB cross-section preparation was used here. A detailed description of the barite sample preparation procedures applied in this study for particle cross-sections and cross-section TEM lamellae is given in Weber et al. (2016). A minimum of two TEM lamellae of each sampling

232 date was prepared and thoroughly characterized.

233

\subsubsection{Transmission electron microscopy (TEM)}

A FEI Tecnai $G^{2}$ electron microscope (FEI Company, The Netherlands) (Luysberg et al., 2016) operated at $200 \mathrm{kV}$ accelerating voltage was used to record selected area electron diffraction (SAED) patterns and scanning transmission electron microscopy (STEM) images using a high-angle annular dark-field (HAADF) detector.

239 Elemental maps were acquired by energy dispersive x-ray (EDX) mapping using a FEI

240 Titan $G^{2} 80-200$ electron microscope (Kovacs et al., 2016) equipped with an EDX system in 241 the ChemiSTEM ${ }^{\mathrm{TM}}$ design (FEI Company, The Netherlands) operated at $80 \mathrm{kV}$ accelerating 242 voltage. The ChemiSTEM ${ }^{\mathrm{TM}}$ design consists of an annular orientation of four large-area, 243 windowless SDD detectors in the Super- $\mathrm{X}^{\mathrm{TM}}$ geometry around the sample area, resulting in 244 improved detection limits compared to the standard design. 


\section{Results and Discussion}

\subsection{Macroscopic results}

248 The macroscopic results of the Ra-uptake experiment conducted in this study are displayed 249 in Fig. 3 and summarized in Table 1. The macroscopic results obtained in this study are in 250 good agreement with a large number of experiments discussed in detail in Brandt et al. 251 (2015). In particular, these data sets indicate a Ra uptake of more than $99 \%$ into the solid 252 after stage 2, and the Ra concentration reaches a plateau in stage 3 (broken line in Fig. 3;

253 Brandt et al., 2015), which was earlier discussed as approach to equilibrium between solid 254 and solution. The $\mathrm{Ra} / \mathrm{Ba}$ ratio after reaching equilibrium state is about $2 \cdot 10^{-3}$ and therefore, 255 the molar volume change and the change in solubility associated with the replacement 256 process can be considered negligible. As a conclusion, no internal microstructural changes 257 would be expected based on the molar volume change or the difference of solubility between 258 parent and resulting phase.

259 Several representative solid samples for further analyses were taken in order to follow the 260 possible internal changes related to the stages of Ra-uptake: two samples in stage 1, one 261 sample at the minimum Ra-concentration at stage 2 and two samples within stage 3 . For 262 comparison, a sample from the study of Brandt et al. (2015) taken at stage 3 was included in 263 the analyses to make a direct link to this study and to the earlier study of Klinkenberg et al. 264 (2014). 


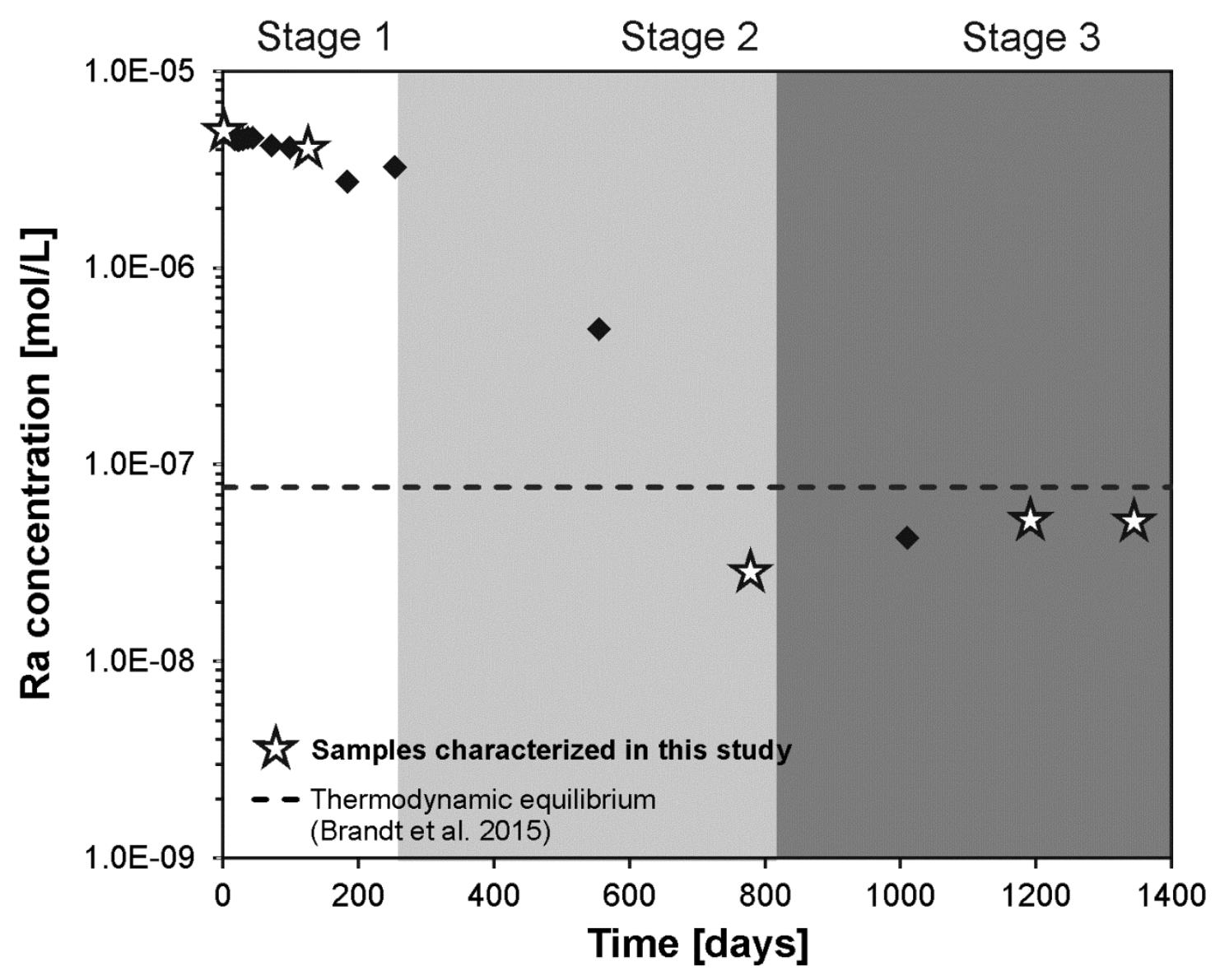

266 Fig. 3. Temporal evolution of the aqueous Ra concentration in the Ra-uptake experiment providing 267 the samples for the microscopic study. Sampling of solid samples is marked with a $\star$. The 268 thermodynamic equilibrium concentration was calculated using an interaction parameter of $\mathrm{a}_{0}=1$ 269 (Vinograd et al., 2013).

$271 \quad$ Table 1

272 Overview of solid samples from $\mathrm{Ra}$ uptake experiments and the Ra-free reference experiment.

273 Experiment 2 was discussed in detail in Brandt et al. (2015) and Klinkenberg et al. (2014).

\begin{tabular}{ccccc}
\hline Sample & Experiment & $\begin{array}{c}\text { Time } \\
\text { [days] }\end{array}$ & $\begin{array}{c}\text { Ra concentration in solution } \\
{[\mathrm{mol} / \mathrm{L}]}\end{array}$ & Stage \\
\hline Initial barite & & 0 & 0 & 0 \\
\hline Exp1_1a & Experiment 1 & 1 & $4.90 \cdot 10^{-6}$ & 1 \\
Exp1_1b & Experiment 1 & 126 & $4.03 \cdot 10^{-6}$ & 1 \\
Exp1_2 & Experiment 1 & 779 & $2.82 \cdot 10^{-8}$ & 2
\end{tabular}




\begin{tabular}{ccccc} 
Exp1_3a & Experiment 1 & 1192 & $5.20 \cdot 10^{-8}$ & 3 \\
Exp1_3b & Experiment 1 & 1345 & $5.20 \cdot 10^{-8}$ & 3 \\
\hline Exp2_3 & Experiment 2 & 602 & $5.03 \cdot 10^{-8}$ & 3 \\
\hline Ref1 & Reference 1 & 1 & 0 & \\
Ref2 & Reference 1 & 127 & 0 & \\
Ref3 & Reference 1 & 505 & 0 & \\
Ref4 & Reference 1 & 898 & 0 & \\
\hline
\end{tabular}

274

275

$276 \quad 3.2 \quad$ Macro porosity and connectivity of pores and their temporal evolution of Ra-free

277 reference samples

278 Numerous cross-sections of the initial barite were already prepared and discussed in Weber 279 et al. (2016). The typical microstructure of this barite comprises macropores and nanometer

280 scaled pores. Fast pathways for the uptake of Ra via pores would require a connection of 281 pores and openings in the particle surface. However, so far the existence of an open pore 282 network could not be shown based on single cross-sectional views. Therefore, FIB-SEM 283 tomography was carried out here on an initial barite and on a grain of a reference experiment 284 without radium after 127 days in solution. In contrast to individual FIB cross sections, the 285 tomography technique provides a three-dimensional (3D) reconstruction of the macropore network as shown in Fig. 4. For example, Fig. 4a shows the SEM image of the initial SL

287 barite particle and Fig. $4 \mathrm{~b}$ the reconstructed particle based on the segmentation. Three pores 288 in the barite surface are visible which indicate the presence of internal porosity with a connection to the outside. Typical for all initial barite samples analyzed by FIB cross-sections and tomography is a connected network of macropores (Fig. 4d) which is at least partially

291 connected to the particle surfaces (Fig. Fig. 4c, orange circles). Compared to the particle 292 volume, some of these pores provide a large entrance for Ra to enter from the aqueous phase 293 by fluid diffusion and reach far into the inside of the particle. In some particles connected 294 macropores were observed, opening up a significant reactive surface area in addition to the 
295 outer particle surface. In addition to the figures presented here, a video of the 3D

296 reconstruction is available in the supplemental information showing the three-dimensinal

297 distribution of the macroporosity.
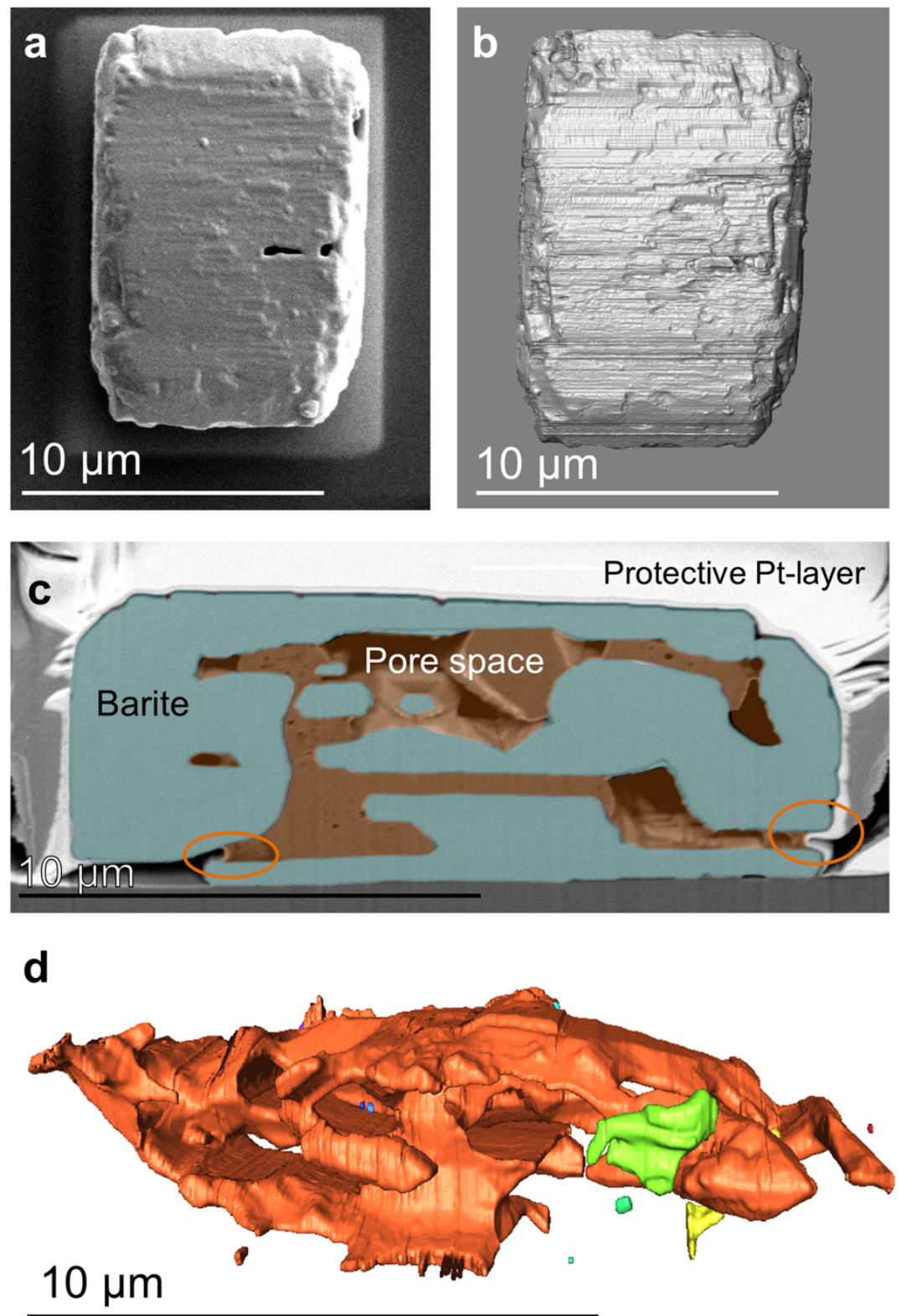

299 Fig. 4. FIB tomography of an initial SL barite particle: a) Top view SEM image of the SL barite

300 particle. b) Top view of the reconstructed particle based on the segmentation of the outer material. c)

301 Cross-section of the reconstructed volume showing the barite particle material selected for segmentation in blue and the selected pore space in orange. The orange circles highlight the open 
macropores and the connection of the internal pores to the bulk fluid. d) Side view of the segmented

304 pore volume. Connected macropores are highlighted in the same color.

306 Under the hypothesis that macropores are a possible pathway of Ra into barite via diffusion

307 within the pore solution, an inhomogeneous uptake of Ra into barite would be expected

308 owing to our observation that not all macropores are connected. Accordingly, the uptake may

309 vary from particle to particle. Furthermore, it should be considered that one third of the 2D

310 barite cross-sections did not show any porosity. In comparison to the initial sample, similar

311 observations were made for the reference sample after 127 days. Connected macropores were

312 observed in the FIB-SEM tomography of this sample as well, which were oriented mostly

313 parallel to the outer surfaces of the particle (Fig. 5).

314 The evolution of the macroporosity was analyzed in detail by image analysis of FIB cross-

315 sections from day 1, 127, 505 and 898 in order to identify whether the macroporosity inside

316 the barite changes during recrystallization. The resulting area-based porosity is given in Table

317 2. No error is specified here as the determination is only semi-quantitative due to the

318 limitations imposed by 2D cutting effects. Despite of these limitations, it should be still

319 possible to observe a relative trend in the area-based porosity. However, the present data does

320 not show a clear evolutional trend of the porosity. 


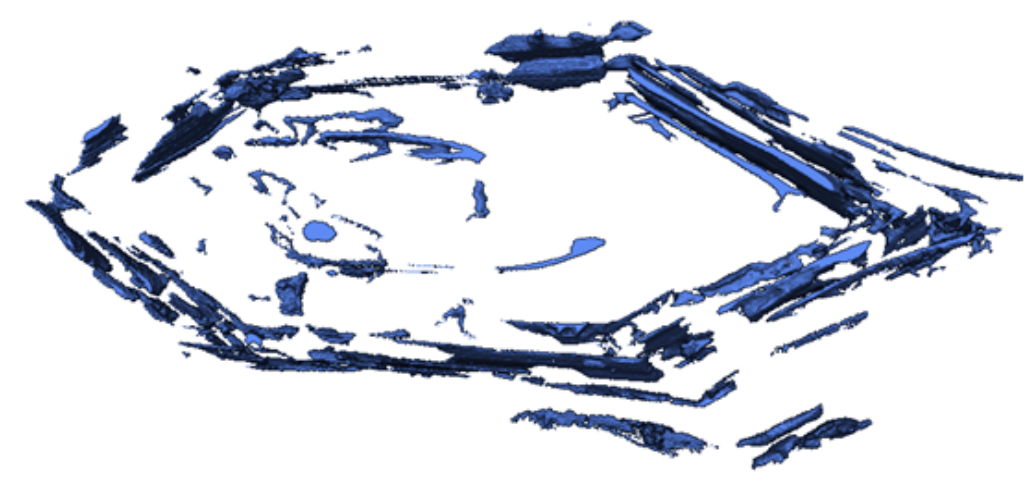

$10 \mu \mathrm{m}$

323 Fig. 5. FIB tomography reconstruction of a particle after equilibration in $0.1 \mathrm{~mol} / \mathrm{L} \mathrm{NaCl}$ for 127 days.

325 Table 2 Evolution of macroporosity inside Ra-free reference barite particles based on image analysis.

\begin{tabular}{cccc}
\hline Sample & $\begin{array}{c}\text { Time } \\
\text { [days] }\end{array}$ & $\begin{array}{c}\text { Number of } \\
\text { analyzed } \\
\text { cross-sections }\end{array}$ & $\begin{array}{c}\text { Area-based } \\
\text { porosity } \\
{[\%]}\end{array}$ \\
\hline Ref1 & 1 & 11 & 1.5 \\
Ref2 & 127 & 11 & 1.7 \\
Ref3 & 505 & 5 & 2.3 \\
Ref4 & 898 & 11 & 2.0 \\
\hline
\end{tabular}

\subsection{Temporal evolution of the nano-scaled pores in the Ra-free reference samples}

328 In addition to the evolution of the macropores, nanometer scale pores were identified

329 within barite samples taken at defined times during long-term experiments of up to 898 days

330 (Fig. 6). Similar as described in Weber et al. (2016), SEM observations of the outside of all

331 Ra-free reference samples (Fig. 6a,d) as well as the detailed observations in FIB cross-

332 sections (Fig. 6b,e) and HAADF STEM images (Fig. 6c,f) indicate the presence of a layered

333 structures formed by nano-scale pores. Dark HAADF STEM contrast indicate a high content

334 of nano-scale porosity whereas bright areas indicate absence of nano-scale porosity. Within 
335898 days, the main change that was observed on the outside of the particles is a smoothening 336 of the particle surfaces and a tendency of particles to merge. However, very little or no

337 change of the internal microstructure was observed. Even after 898 days the layered internal

338 structures are clearly visible (Fig. 6e, f). The width of the layered structures, their orientation

339 and other characteristic features are very well comparable at all stages of the reference

340 experiments. This can be taken as an indication of a very stable internal microstructure of

341 barite. The high stability of fluid inclusions in barite was also recently reported by Jamieson

342 et al. (2016) where they were proposed to preserve the conditions of physical and chemical

343 processes at the seafloor. However, the same barite powders as used in the presented

344 experiments appear to undergo significant recrystallization on the time scale of the

345 experiment according to ${ }^{133}$ Ba tracer experiments (Bosbach et al., 2010; Curti et al., 2010).

346 Therefore, either the recrystallization in Bosbach et al. (2010) and Curti et al. (2010) may

347 have been triggered by the presence of ${ }^{133} \mathrm{Ba}$, or the fluid inclusions are stable against the 348 recrystallization of barite itself. 

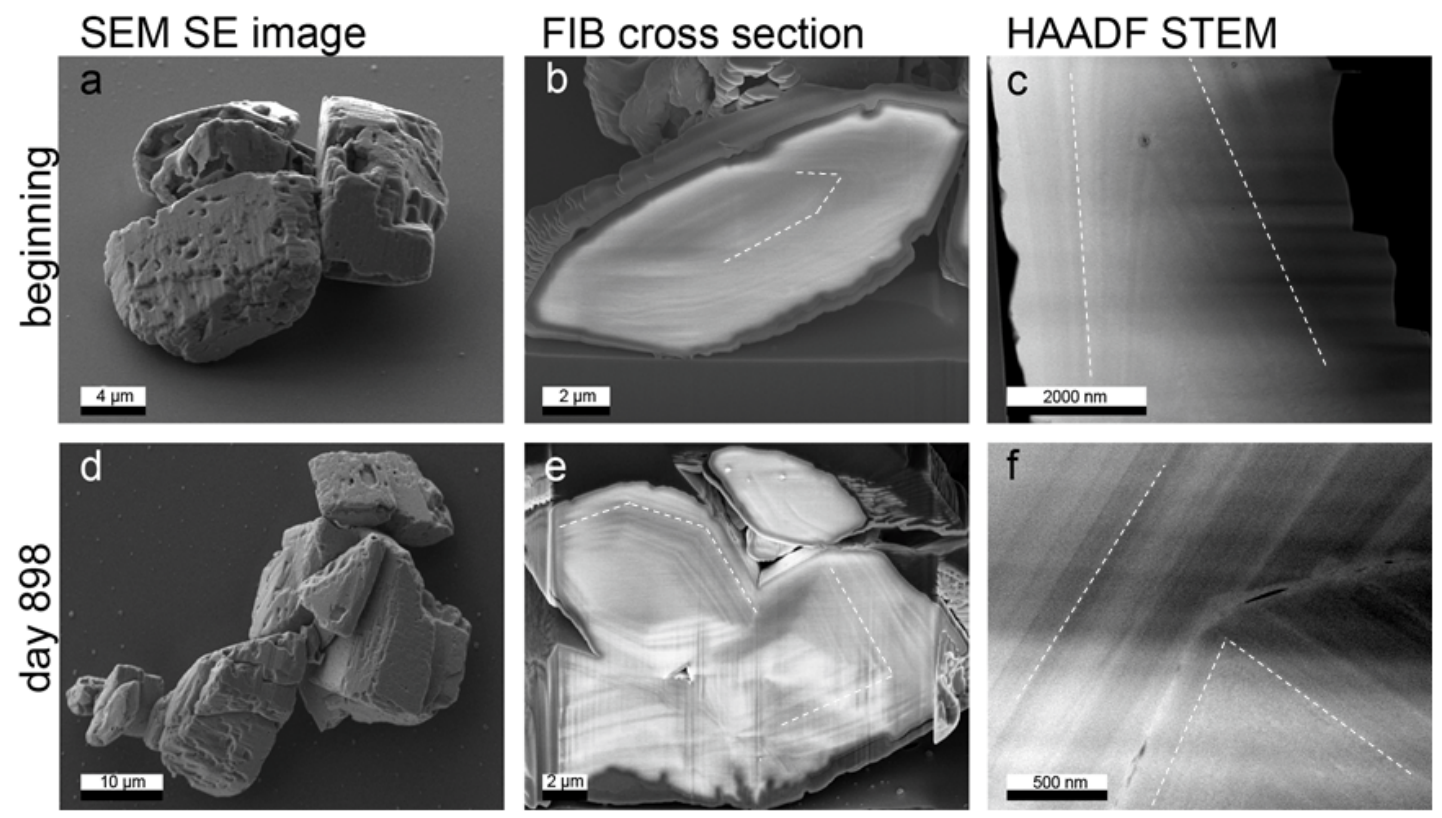

351 Fig. 6. Temporal evolution of the internal microstructure of SL barite from the Ra-free reference experiment at the beginning $(a-c)$ and after 898 days $(d-f)$. SEM images of the barite particles are given in (a) and (d), while (b) and (e) show SEM images of FIB cross-sections. The nano-scale porosity is visible as a layered structure in HAADF STEM images (c) and (f), where dashed lines trace back the layered structure.

\subsection{Temporal evolution of barite samples from ${ }^{226}$ Ra uptake experiments}

358 During stage 1 no significant changes of the external microstructure could be detected by

359 SEM imaging. At the middle of stage 1 (day 126), the surface of the barite particle in Fig. 7a

360 shows many pores and a very irregular rough surface. The particles remained well separated.

361 At stage 2, the particles started growing together, forming chains (Fig. 7b). In most of the 362 cases they were attached to each other either at the $\{210\}$ surfaces or at the $\{100\}$ surfaces. In

363 a recently published study of Zhang et al. (2017), Van-der-Waals forces are considered as 364 reason for crystallographic oriented attachment of particles. During the Ra uptake and barite recrystallization until stage 3, the barite surface is smoothened (Fig. 7c), and fewer pores than

366 in the previous stages were observed. Later in stage 3, when approaching equilibrium, long 
chains of particles have formed building a complex three-dimensional structure. In addition, the particles exhibit a further developed euhedral shape compared to the beginning of equilibration. Still large pores are visible in the barite particle surface as indicated in Fig. 7c.
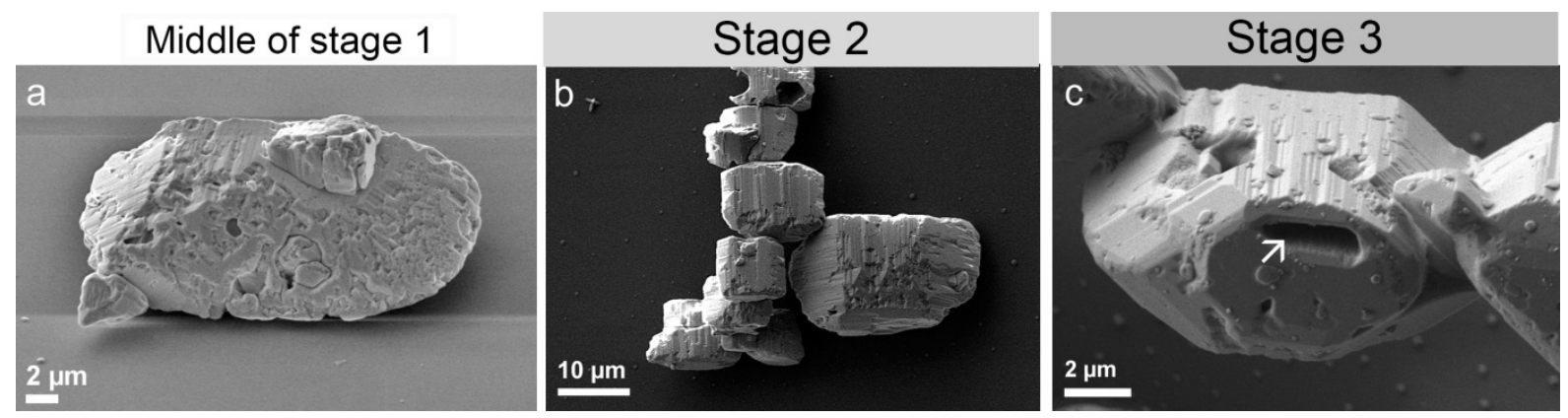

Fig. 7. SEM images showing the effects of recrystallization of barite in the presence of Ra. At the end of stage 1 (a), the crystal surfaces are very rough and many pores are visible. The Ra-barites start growing together and show a smoothing of the crystal surfaces at stage 2 (b). The particle shape evolves more towards euhedral barite shape. At the stage 3 (c), the Ra-barite particles are grown together. Crystal surfaces are smoother with new precipitates on them; the arrow indicates a pore.

Fig. 8 shows FIB cross-sections of radiobarites at different stages of the Ra-uptake. In the presence of $\mathrm{Ra}$, the internal microstructure of the barite grains becomes instable and changes significantly already during stage 1 of the Ra uptake, while their external structure remains essentially unchanged. The internal microstructure now contains larger pores while the layered nano-scale pore structures are partially or even completely eliminated (Fig. 8c). In contrast to the Ra-free reference, the area-based macroporosity reaches a clear maximum in the middle of stage 1 (Table 3 ). This can be taken as an indication that the nanometer-scale pores coalesce to macropores during the Ra uptake, minimizing the surface free energy. The HAADF STEM images displayed in Fig. 9a-c shows the remaining layered structure consisting of nano-scale pores as well as of macropores in direct vicinity. 
At stage 2, when the minimum Ra concentration in solution is reached, further coalescing

390 of the nano-scaled pores has led to the formation of additional macropores and no layered

391 structure could be observed in HAADF STEM and SEM images of FIB cross sections

392 anymore (Fig. 8e,f; Fig. 9d-f). In comparison, even later in the reference experiment, layered

393 structures are still clearly visible (Fig. 6e,f). The FIB section at this stage of the Ra uptake

394 indicates that some of the pores are oriented in the same direction as the former layered 395 structures whereas some are also irregularly distributed within the barite particles (Fig. 8e,f).

396 The area-based macroporosity at this stage has decreased from ca. $6.6 \%$ back to $3.7 \%$

397 (Table 3). Additionally, as discussed in the later part of this study, the uptake of Ra and its

398 heterogeneous distribution could be indicated by brighter contrasts in HAADF STEM images

399 (Fig. 9d-f, Fig. 10).

400 During the final stage 3 of the Ra uptake experiments, macropores of several micrometers

401 in length which are typically oriented parallel to the outer crystal surfaces occur in some of 402 the FIB cross-sections (Fig. 8 g). In the HAADF STEM images an outer rim of higher density 403 becomes visible, most likely indicating the formation of coherent newly formed $(\mathrm{Ba}, \mathrm{Ra}) \mathrm{SO}_{4}$ 404 (Fig. 9 h). Inside this rim, areas of increased nano-scale porosity are observed (Fig. 9 i). 405 Additional HAADF STEM and TEM images showing this dense rim and the newly formed 406 inner nano-scale porosity are given in the Fig. S1 and S2 of the supplemental information. 

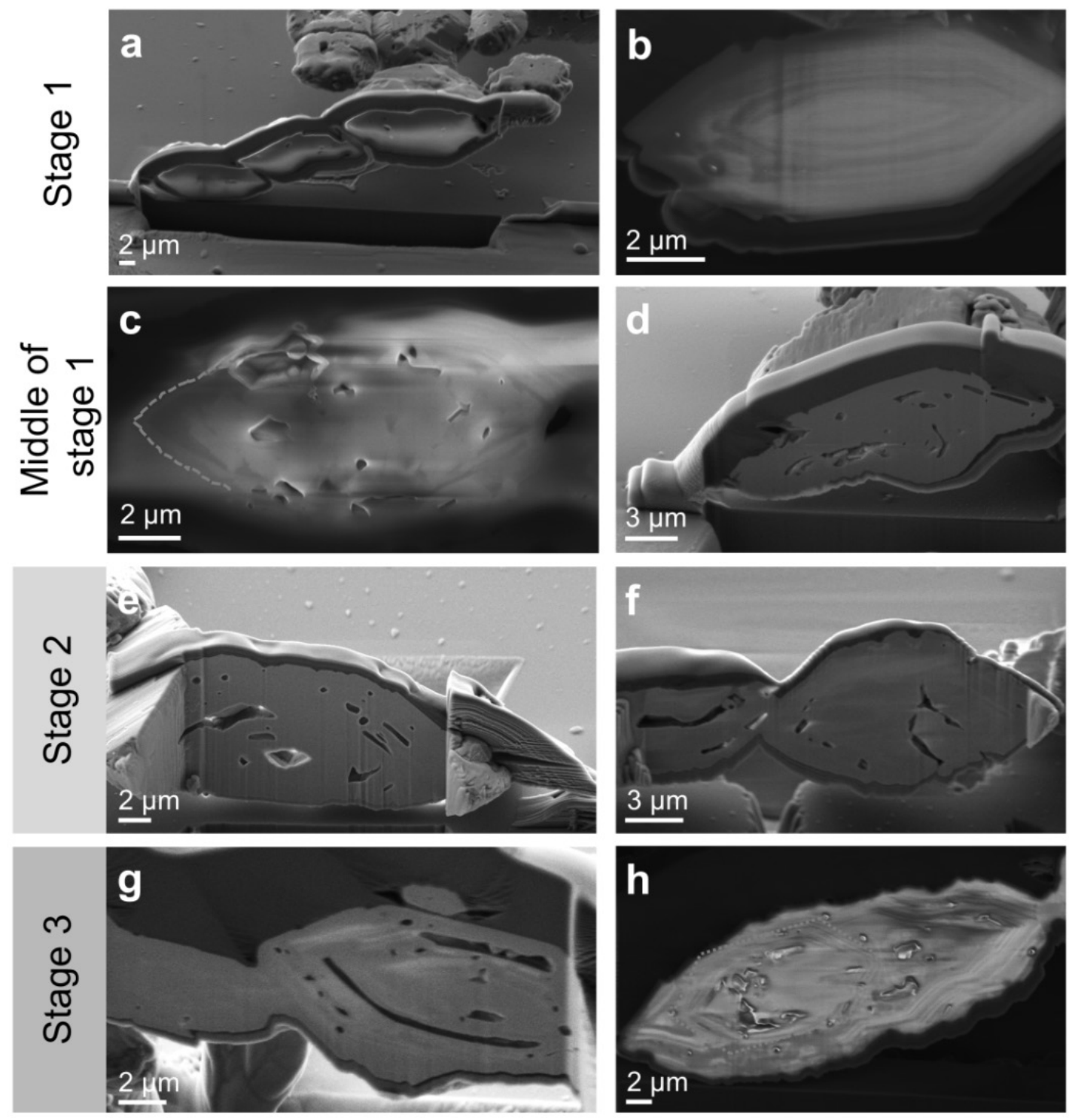

409 Fig. 8. FIB-cross sections of Ra-barites from different stages. In stage 1, particles with macropores (a)

410 are present as well as particles with a layered structure (b). This layered structure starts to disappear in

411 the middle of stage 1 (c) and more elongated pores can be observed (d). At stage 2, hollow barite

412 cores are observed (e) as well as particles growing together (f). At stage 3, the macropores grow

413 together $(\mathrm{g})$ and particles are completely grown together to new particles $(\mathrm{h})$. 

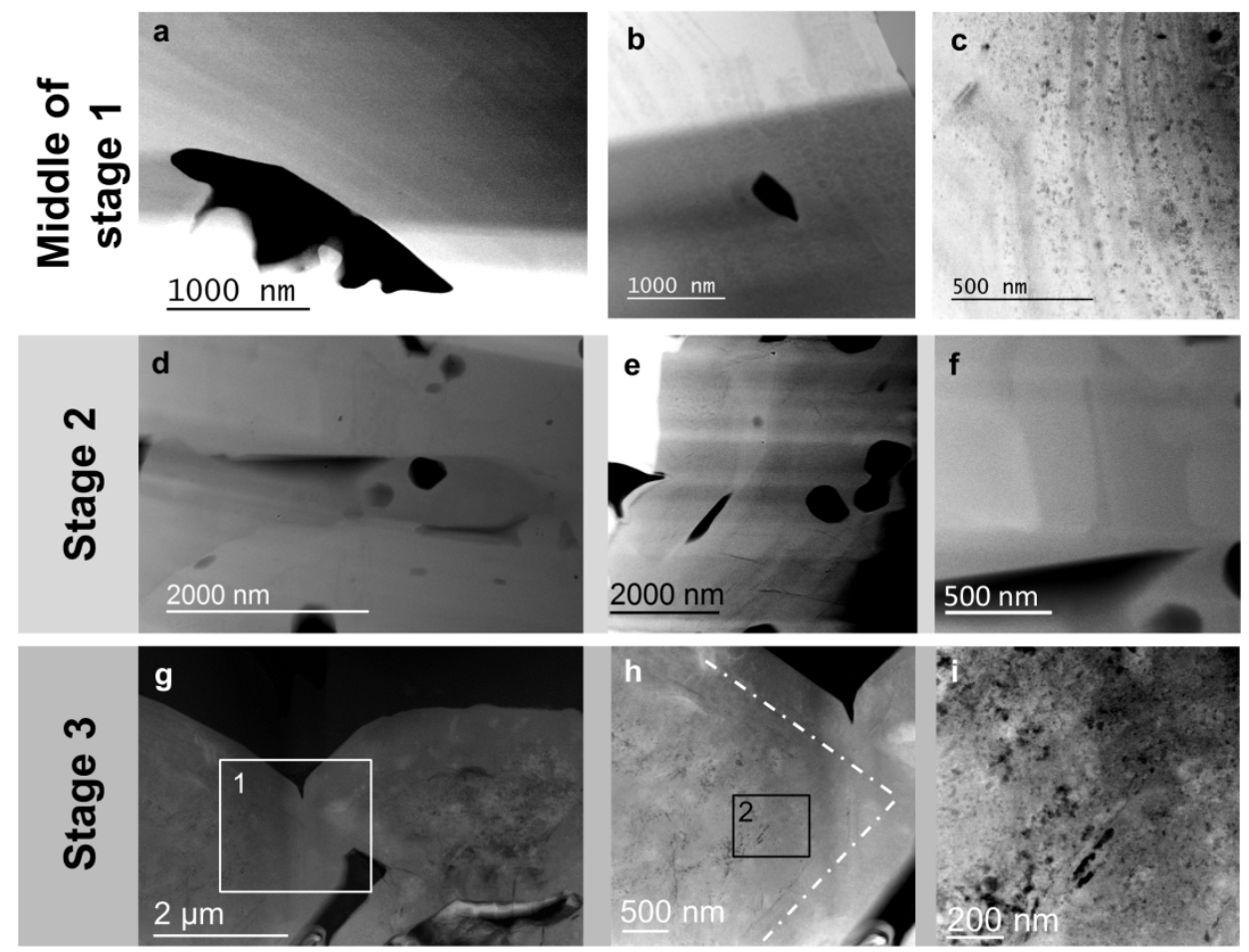

416 Fig. 9. HAADF STEM images of the Ra-barite sampled at different stages of recrystallization. The

417 Ra-barites from the middle of the stage 1 clearly display a layered structure (a) and (b). At higher

418 magnification (c), it is visible that the layers consist of larger nano-scale pores similar as observed in

419 the beginning of stage 1 . At stage 2, no layered structure can be observed anymore (d) - (f). Visible

420 contrast variations could not be attributed to nano-scale porosity but could indicate an enrichment of

421 Ra. At the stage $3(\mathrm{~g})$, a massive outer rim is visible. The area (1) is magnified in (h) showing this

422 massive rim. The particles contain newly formed nano-scale porosity in the area (2) which is 423 magnified in (i). 
Table 3 Evolution of area-based macroporosity during Ra uptake based on semi-quantitative image analysis.

427

428

429

430

431

432

\begin{tabular}{cccc}
\hline Sample & Stage & $\begin{array}{c}\text { Number of analyzed } \\
\text { cross sections }\end{array}$ & $\begin{array}{c}\text { Area-based porosity } \\
{[\%]}\end{array}$ \\
\hline Exp1_1a & 1 beginning & 9 & 3.5 \\
Exp1_1b & 1 middle & 12 & 6.6 \\
Exp1_2 & 2 & 4 & 3.7 \\
Exp1_3 & 3 & 25 & 2.3 \\
\hline
\end{tabular}

\subsection{Temporal evolution of the spatial distribution of Ra}

High resolution STEM-EDX measurements and mappings were performed to track the Ra uptake and $(\mathrm{Ba}, \mathrm{Ra}) \mathrm{SO}_{4}$ solid-solution formation. No Ra was detected within FIB-lamellae of barite particles of sample Exp1_1b taken within the first half of stage 1 with STEM-EDX. Based on the Ra-concentration of the corresponding aqueous solution sample, only a very small amount of Ra should be present inside the barite sample at this stage. Since no Ra was detected by EDX spectroscopy, the Ra-concentration inside the barite solid is probably below the detection limit at the first half of stage 1 . In contrast, Ra was clearly identified with the same technique in sample Exp1_2 taken at the time corresponding to the minimum Ra concentration in solution of stage 2 (Fig. 10). STEM-EDX mappings taken from the same sample indicate an inhomogeneous $\mathrm{Ra}$ and $\mathrm{Ba}$ distribution at this stage of the Ra uptake experiment (Fig. 10 b). The sample presented in Fig. 10a shows differences in the contrast indicating the presence of inhomogeneity. In this sample, the bright area is located between two pores. The EDX mapping shows a Ra distribution which qualitatively matches the HAADF contrast variations (Fig. 10b and c). A significant amount of Ra in the range of more than $1 \mathrm{at} \%$ is present in the yellow area of Fig. 11b. Higher Ra concentrations typically were observed near pores in the EDX mappings indicating that Ra appears to replace Ba (Fig. 11a). 
446 Additional STEM-EDX mapping of samples from stage 2 demonstrating the inhomogeneous

447 Ra distribution within the barite can be found in Fig. S3 - S5 of the supplemental information.

448 Fig. 11c shows the STEM-EDX mapping of the Ra containing sample at stage 3, 449 corresponding to the approach of equilibrium between aqueous solution and solid. Based on 450 mass balance between solid and solution and assuming a homogeneous distribution of $\mathrm{Ra}$ in 451 the solid, the calculated Ra concentration of the barite particles was $60 \mathrm{ppm}$. Unfortunately, 452 this is well below the detection limit of the applied EDX spectroscopy system. In the case of 453 a homogeneous $\mathrm{Ra}$ distribution, consequently no Ra peak would be expected. The EDX 454 spectrum corresponding to c confirms this expectation (Fig. 11d). Furthermore, the Ra455 concentration in solution remained stable near the calculated equilibrium concentration 456 during stage 3. Therefore, we deduce indirectly that Ra was distributed homogeneously in 457 stage 3, i.e. a complete ( $\mathrm{Ra}, \mathrm{Ba}) \mathrm{SO}_{4}$ solid has formed, which is in equilibrium with the aqueous solution. Additional STEM-EDX measurements are given in Fig. S6 and S7 of the supplemental information.

460
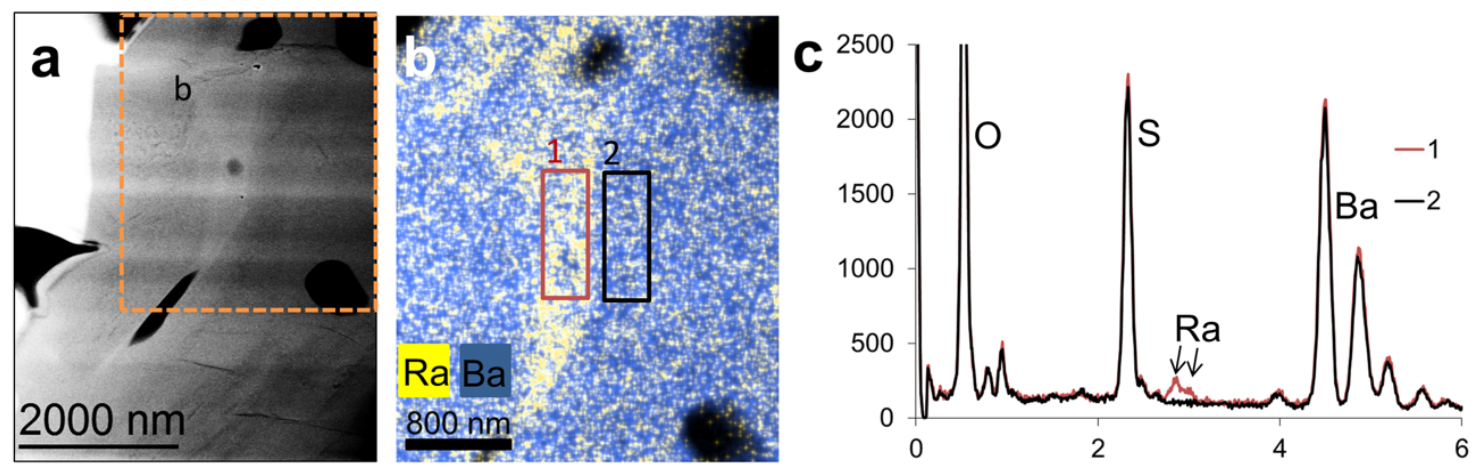

462 Fig. 10. Ra distribution inside the barite at stage 2. (a) HAADF-STEM image of sample Exp1_2 taken at stage 2, (b) corresponding STEM-EDX mapping of the area indicated in (a) by broken lines, (c) EDX-STEM spectra taken from the areas (1) and (2) in (b). The spectrum of area 1 shows clear signal of $\mathrm{Ra}$, whereas no Ra signal is visible in spectrum 2 . 

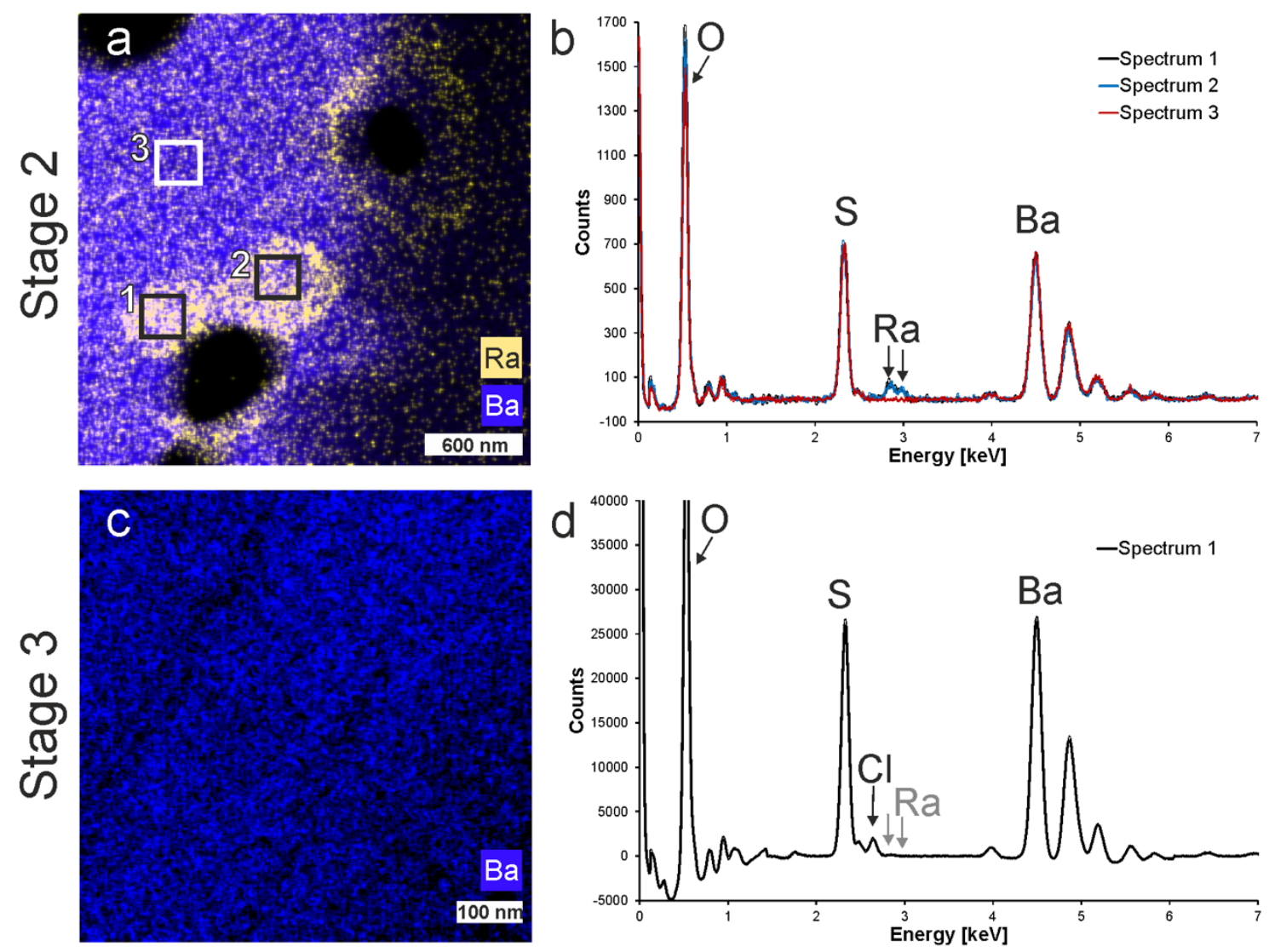

Fig. 11. Temporal evolution of the radium distribution from stage 2 to stage 3. (a) STEM-EDX mapping of $\mathrm{Ra}$ (yellow) and $\mathrm{Ba}$ (blue) at stage 2 (sample Exp1_2). The black areas are the macropores. (b) EDX spectra of the labeled areas 1, 2, and 3 (c) STEM-EDX mapping of barium at stage 3 (sample Exp2_3) (d) corresponding EDX spectrum of the whole area, no Ra signal detected.

472 The expected positions of the Ra-L peaks in the spectrum are marked by gray arrows.

\section{Summary and conclusion}

476 New insights into the mechanism of the Ra uptake into barite were obtained by comparing

477 barite and Ra-barite samples applying a state-of-the-art high resolution microscopic

478 approach. Characteristic for the initial barite sample was a connected macroporosity offering 479 a fast pathway for Ra into the particle volume via fluid diffusion. The evolution of the 
microstructure and the Ra distribution within barite was characterized at different stages of 481 the Ra-uptake in order to understand the uptake mechanism.

482 In the presence of $\mathrm{Ra}$, the surfaces of the barite samples became smoother with time, 483 similar to the samples of the Ra-free recrystallization experiments. For the latter samples, 484 also no significant changes were observed for the internal microstructure, even after 485 recrystallization times of up to 898 days. In contrast to that, the overall porosity of the barite 486 which was recrystallized in the presence of Ra changed in several steps: At the beginning, the 487 nano-scale fluid inclusions disappeared, probably due to coalescing to new macropores, 488 which could be favorable in the context of surface energy minimization. Later, the Ra-barite 489 particles contained a dense rim structure with no porosity and an inner core of nano-scale 490 porosity. In addition, the amount of macroporosity increased temporarily at stages 1 and 2 , and was finally reduced again to a similar level as observed in the initial and reference samples. Energy minimization can be considered as a reason for reduction of macroporosity 493 after the minimum observed in the radium concentration in solution. In addition, some 494 available studies suggest that the reactivity of nanopores differs greatly from that of other 495 pores (Stack, 2014, Stack, 2015). Therefore, the presence of nano-scaled fluid inclusions in 496 the starting material could provide additional energy triggering the exchange process.

497 During stage 1, no Ra was detected in the solid by EDX spectroscopy. Ra may have migrated within the aqueous phase into the barite samples and may be still contained within 499 the macropores. During stage 2, Ra was distributed inhomogeneously within the barite 500 crystals. It was found to be concentrated in rims around some macropores. During stage 3, the 501 Ra concentration was below the detection limit of EDX spectroscopy. A homogeneous Ra 502 distribution in the particles and a stable aqueous Ra concentration support the conclusion that 503 a thermodynamic equilibrium was reached at stage 3. 

diffusion through macropores into the crystal volume and a dissolution-reprecipitation from

506 the inside to the outside of the particles leading to a homogenous Ra distribution (Fig. 12). At

507 the scale of the experiments, residual porous structures on the inside of the particles remain, 508 although the solution composition approaches the predicted equilibrium of this solid-solution aqueous solution system.

510

511

Initial barite

layered structure
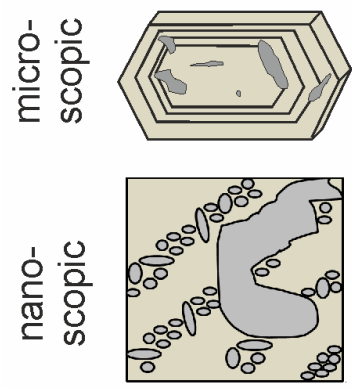

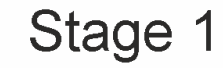

pores filled with $\mathrm{Ra}$ containing solution
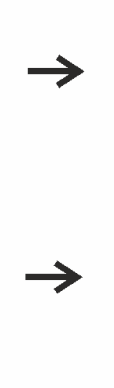
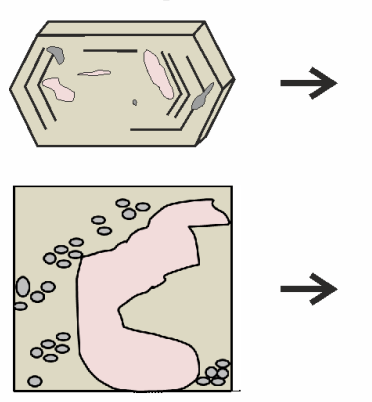

Stage 2

Ra enters barite
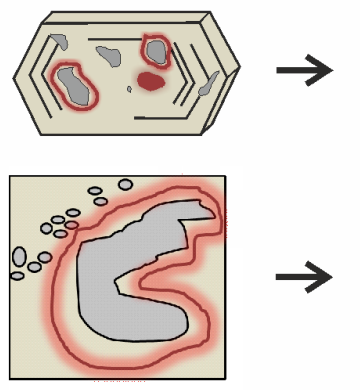

Stage 3

(Ba, Ra) $\mathrm{SO}_{4}$ solid solution
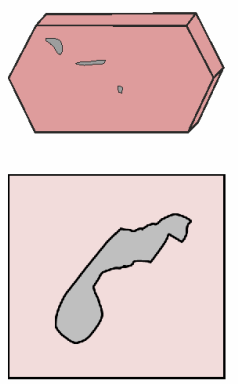

512 Fig. 12. Schematic summary of the process of Ra uptake into barite. Evolution of the micro/nano structure in the presence of Ra.

Our results indicate that barite can be destabilized and significantly reconstructed internally in the presence of a Ra-containing aqueous solution even though it appears to be quite stable and close-to-equilibrium from the outside. The reactivity of the barite powders containing fluid inclusions as investigated here could be utilized to directly remediate Ra from aqueous solution into a thermodynamically stable form or to stabilize $(\mathrm{Ba}, \mathrm{Ra}) \mathrm{SO}_{4}$ precipitated via coprecipitation. The results also indicate that it is possible to take up more Ra into barite than

521 thermodynamically stable, leading to inhomogeneities of the Ra concentration within barite 522 particles. During the course of further equilibration, it can be expected that such $\left(\mathrm{Ba}, \mathrm{Ra}^{2} \mathrm{SO}_{4}\right.$

523 solid solutions which may be formed via co-precipitation in contact with a Ra-free solution 
524 will release the surplus of Ra over a long time until equilibrium is reached. In this case, the 525 addition of barite would keep the Ra in solution stable at a very low level.

526 Finally, regarding the implementation of the $(\mathrm{Ba}, \mathrm{Ra}) \mathrm{SO}_{4}$ solid solution into safety 527 assessments for deep geological disposal of spent nuclear fuel, the details of the Ra uptake in 528 barite need to be understood. From the presented results, the attribution of the final steady 529 state of the Ra concentration in solution to a homogeneous solid allows to take credit from 530 this system.

\section{Acknowledgements}

534 Prof. J. Mayer is acknowledged for his scientific input and discussion of TEM results. We 535 are grateful to D. Meertens and A. Savenko for their support with the FIB preparation. Dr. 536 Roland Schierholz is acknowledged for access to the analysis computer for the 3D 537 tomography. The Swedish Nuclear Fuel and Waste Management Ageny (Svensk 538 Kärnbränslehantering Aktiebolag) is acknowledged for partially financing of this study. J. 539 Barthel and M. Kruth acknowledge funding within the core facilities initiative of the German 540 Research Foundation (DFG) under the grant number MA 1280/40-1. We are grateful to Dr.

541 G. Deissmann for the fruitful discussions. 


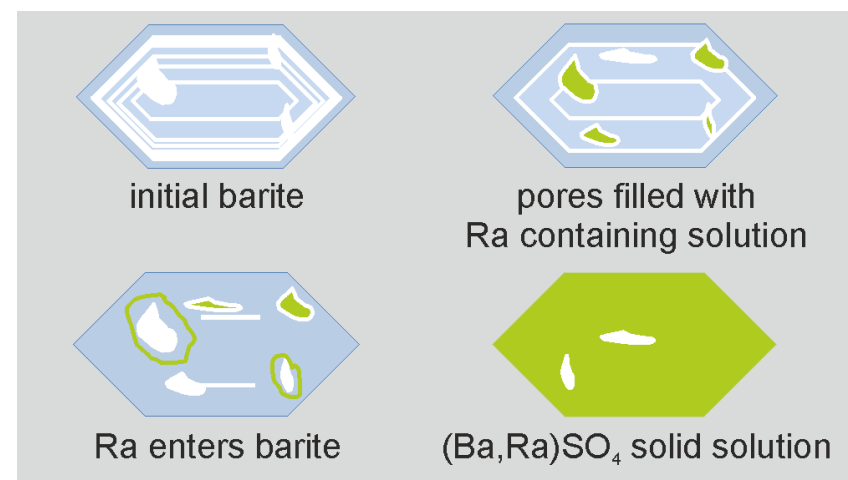

546

547

Highlights:

548 (maximum 125 characters, including spaces, per bullet point)

- Completely different evolution of the microstructure in Ra uptake and Ra-free recrystallization experiments observed

- Complete re-equilibration from a temporary, inhomogeneous Ra distribution to a homogeneous $(\mathrm{Ba}, \mathrm{Ra}) \mathrm{SO}_{4}$ solid solution

- Uptake of Ra into barite by a special case of dissolution-reprecipitation process proceeding from the inside of the particle to the outside in addition to the uptake from the outside

\section{Corresponding Author}

$559 *$ New affiliation: Oak Ridge National Laboratory, Phone: 865-576-7184, E-Mail:

560 weberj@ornl.gov 
563 Al Attar, L., Safia, B., Abdul Ghani, B., Chemical composition of scales generated from oil industry and correlation to radionuclide contents and gamma-ray measurements of ${ }^{210} \mathrm{~Pb}$. Environ. Pollut. 2016, 210, 246-252. DOI: $10.1016 /$ j.envpol.2015.12.007

566 Altree-Williams, A., Pring, A., Ngothai, Y., Brugger, J., Textural and com-positional complexities resulting from coupled dissolution-reprecipitation reactions in geomaterials: Earth-Science Reviews, 2015, 150, 628-651. DOI: $\underline{10.1016 / j . e a r s c i r e v .2015 .08 .013}$

Attallah, M. F., Hamed, M. M., El Afifi, E. M., Aly, H. F., Removal of ${ }^{226}$ Ra and ${ }^{228}$ Ra from TENORM sludge waste using surfactants solutions. J. Environ. Radioact. 2015, 139, 78-84. DOI: 10.1016/j.jenvrad.2014.09.009

Böhlke, J. K., Irwin, J. J., Brine history indicated by argon, krypton, chlorine, bromine, and iodine analyses of fluid inclusions from the Mississippi Valley type lead-fluorite-barite deposits at Hansonburg, New Mexico. Earth Planet. Sci. Lett. 1992, 110, 51-66. DOI: $\underline{10.1016 / 0012-821 X(92) 90038-W}$

Bosbach, D., Boettle, M., Metz, V. SKB Technical Report. 2010, TR-10-43.

Blount, C.W. Barite solubilities and thermodynamic quantities up to $300{ }^{\circ} \mathrm{C}$ and 1400 bars. Amer. Mineral., 1977, 62, 9-10.

Brandt, F., Curti, E., Klinkenberg, M., Rozov, K., Bosbach, D., Replacement of barite by a $(\mathrm{Ba}, \mathrm{Ra}) \mathrm{SO}_{4}$ solid solution at close-to-equilibrium conditions: A combined experimental and theoretical study. Geochim. Cosmochim. Acta 2015, 155, 1-15. DOI: $\underline{10.1016 / j . g c a .2015 .01 .016}$

Bruno, J., Bosbach, D., Kulik, D., Navrotsky, A., Chemical thermodynamics of solid solutions of interest in nuclear waste management: a state-of-the-art report; Mompean, 

F. J.; Illemassene, M.; Perrone, J., Eds.; OECD Nuclear Agency (NEA): Paris, France, 2007; Vol. 10.

Chalupnik, S., Wysocka, M. Radium removal from mine waters in underground treatment installations. J. Environ. Radioact. 2008, 99, 1548-1552. DOI: $\underline{10.1016 / \text { i.jenvrad.2007.12.024 }}$

Curti, E., Fujiwara, K., Iijima, K., Tits, J., Cuesta, C., Kitamura, A., Glaus, M., Müller, W. Radium uptake during barite recrystallization at $23 \pm 2{ }^{\circ} \mathrm{C}$ as a function of solution composition: An experimental ${ }^{133} \mathrm{Ba}$ and ${ }^{226} \mathrm{Ra}$ tracer study. Geochim. Cosmochim. Acta 2010, 74, 3553-3570. DOI: $\underline{10.1016 / j . g c a .2010 .03 .018}$

Gorski, C.A., Fantle, M.S., Stable Mineral Recrystallization in Low Temperature Aqueous Systems: A Critical Review. Geochim. Cosmochim. Acta 2016, 198, 439-465. DOI: 10.1016/j.gca.2016.11.013

Grandia, F., Merino, J., Bruno, J. Assessment of the radium-barium co-precipitation and its potential influence on the solubility of Ra in the near-field, SKB Technical Report TR08-07, SKB: Stockholm, Sweden, 2008.

Hanor, J.S. Barite-celestine geochemistry and environments of formation. Review in Mineralogy and Geochemistry, 2000, 40.1, 193-275. DOI: 10.2138/rmg.2000.40.4

Heberling, F., Paulig, L., Nie, Z., Schild, D., Finck, N. Morphology Controls on Calcite Recrystallization. Environ. Sci. Technol. 2016, 50, 11735-11741. DOI: 10.1021/acs.est.6b04011

Hellmann, R., Cotte, S., Cadel, E., Malladi, S., Karlsson, L.S., Lozano-Perez, S., Cabié, M., Seyeux, A., Nanometre-scale evidence for interfacial dissolution-reprecipitation control of silicate glass corrosion. Nature materials, 2015, 14.3 307-311. 
609 Holzer, L., Indutnyi, F., Gasser, Ph., Münch, B., Wegmann, M., Three-dimensional analysis 610 of porous BaTiO3 ceramics using FIB nanotomography, J. Microsc. 2004, 216, 84-95. $611 \quad$ DOI: $10.1111 / \mathrm{j} .0022-2720.2004 .01397 . \mathrm{x}$

612 International Atomic Energy Agency (IAEA). The environmental behaviour of radium: 613 revised edition; IAEA: Vienna, Austria, 2014.

614 Jamieson, J. W., Hannington, M. D., Tivey, M. K., Hansteen, T., Williamson, N. M. B., 615 Stewart, M., Fietzke, J., Butterfield, D., Frische, M., Allen, L. Precipitation and growth 616 of barite within hydrothermal vent deposits from the Endeavour Segment, Juan de Fuca 617 Ridge. Geochim. Cosmochim. Acta 2016, 173, 64-85. DOI: 10.1016/j.gca.2015.10.021

618 Klinkenberg, M., Brandt, F., Breuer, U., Bosbach, D. Uptake of Ra during the 619 620 621

Kondash, A. J., Warner, N. R., Lahav, O., Vengosh, A. Radium and barium removal through 623 blending hydraulic fracturing fluids with acid mine drainage. Environ. Sci. Technol. 2014, 48, 1334-1342. DOI: 10.1021/es403852h

Kovács, A., Schierholz, R., Tillmann, K. FEI Titan G2 80-200 CREWLEY. J. large-scale 626 Res. Facil. JLSRF 2016, 2, A43.

Kruth, M., Meertens, D., Tillmann, K. FEI Helios NanoLab 460F1 FIB-SEM. J. large-scale 628 Res. Facil. JLSRF 2016, 2, A59.

629 Luysberg, M.; Heggen, M.; Tillmann, K. FEI Tecnai G2 F20. J. large-scale Res. Facil. 630 JLSRF 2016, 2, A77. 
631

632

633

634

635

636

637

638

639

640

641

642

643

644

645

646

647

648

649

650

651

652

653

Meertens, D., Kruth, M., Tillmann, K. FEI Helios NanoLab 400S FIB-SEM. J. large-scale Res. Facil. JLSRF 2016, 2, A60.

Pollok, K., Putnis, C. V., Putnis, A.. Mineral replacement reactions in solid solution-aqueous solution systems: Volume changes, reactions paths and end-points using the example of model salt systems. A.J.S., 2011, 311(3), 211-236. DOI: 10.2475/03.2011.02

Putnis, A., Austrheim, A. Mechanisms of metasomatism and metamorphism on the local mineral scale: The role of dissolution-reprecipitation during mineral re-equilibration. Metasomatism and the Chemical Transformation of Rock. Springer Berlin Heidelberg, 2013. 141-170. DOI: $10.1007 / 978-3-642-28394-9 \_5$

Putnis, C. V., Geisler, T., Schmid-Beurmann, P., Stephan, T., \& Giampaolo, C. An experimental study of the replacement of leucite by analcime. Amer. Miner., 2007. 92(1), 19-26. DOI: 10.2138/am.2007.2249

Putnis, A., and Putnis, C. V., The mechanism of reequilibration of solids in the presence of a fluid phase: Journal of Solid State Chemistry, 2007, 180, 5, 1783-1786. DOI: 10.1016/j.jssc.2007.03.023

Prieto, M., Heberling, F., Rodríguez-Galán, R. M., Brandt, F. Crystallization behavior of solid solutions from aqueous solutions: An environmental perspective. Prog. Cryst. Growth Charact. Mater. 2016, 62, 29-68. DOI: 10.1016/j.pcrysgrow.2016.05.001

Qian, G., Brugger, J., Skinner, W. M., Chen, G., Pring, A.. An experimental study of the mechanism of the replacement of magnetite by pyrite up to 300 C. Geochim. Cosmochim. Acta, 2010, 74(19), 5610-5630. DOI: 10.1016/j.gca.2010.06.035

Rosenberg, Y. O., Metz, V., Ganor, J. Co-precipitation of radium in high ionic strength systems: 1. Thermodynamic properties of the Na-Ra-Cl- $\mathrm{SO}_{4}-\mathrm{H}_{2} \mathrm{O}$ system - Estimating 

$\underline{10.1016 / j . g c a .2011 .06 .042}$

656

657

658

659

660

661

662

663

664

665

666

667

668

669

670

671

672

673

Rosenberg, Y. O., Metz, V., Oren, Y., Volkman, Y., Ganor, J. Co-precipitation of radium in high ionic strength systems: 2. Kinetic and ionic strength effects. Geochim. Cosmochim. Acta 2011b, 75, 5403-5422. DOI: 10.1016/j.gca.2011.07.013

Rosenberg, Y. O., Sadeh, Y., Metz, V., Pina, C. M., Ganor, J. Nucleation and growth kinetics of $\mathrm{Ra}_{\mathrm{x}} \mathrm{Ba}_{1-\mathrm{x}} \mathrm{SO}_{4}$ solid solution in $\mathrm{NaCl}$ aqueous solutions. Geochim. Cosmochim. Acta 2014, 125, 290-307. DOI: $10.1016 /$ j.gca.2013.09.041

Ruiz-Agudo, E., Putnis, C.V., Putnis, A., Coupled dissolution and precipitation at mineralfluid interfaces. Chem. Geol. 2014, 383, 132-146. DOI: 10.1016/j.chemgeo.2014.06.007

Stack, A.G. Next generation models of mineral growth and carbonate mineral growth and dissolution. Ghg, 2014, 4 (3), 278-288. DOI: 10.1002/ghg.1400

Stack, A. G. Precipitation in pores: A geochemical frontier. Rev. Mineral Geochem., 2015, 80, p. $165-190$. DOI: $10.2138 /$ rmg.2015.80.05

Stoica, L., Filip, D., Filip, G., Razvan, A., Radulescu, R. Removal of ${ }^{226}$ Ra(II) from uranium mining and processing effluents. J. Radioanal. Nucl. Chem. 1998, 229, 139-142. DOI: 10.1007/BF02389462

Thoenen, T., Hummerl, W., Berner, U., Curti, E., The PSI/Nagra Chemical Thermodynamic Database 12/07. 2014. Nagra Working Report NAB, 14-49. 
674 Torapava, N., Ramebäck, H., Curti, E., Lagerkvist, P., Ekberg, C. Recrystallization of ${ }^{223}$ Ra

675

676

677

678

679

680

681

682

683

684

685

686

687

688

689

690

691

692

693

694

695

696 with barium sulfate. J. Radioanal. Nucl. Chem. 2014, 301, 545-553. DOI: 10.1007/s10967-014-3170-6

Varley, A., Tyler, A., Smith, L., Dale, P., Davies, M. Mapping the spatial distribution and activity of ${ }^{226} \mathrm{Ra}$ at legacy sites through Machine Learning interpretation of gamma-ray spectrometry data. Sci. Total Environ. 2016, 545-546, 654-661. DOI: $\underline{10.1016 / \text { j.scitotenv.2015.10.112 }}$

Vinograd, V. L., Brandt, F., Rozov, K., Klinkenberg, M., Refson, K., Winkler, B., Bosbach, D. Solid-aqueous equilibrium in the $\mathrm{BaSO}_{4}-\mathrm{RaSO}_{4}-\mathrm{H}_{2} \mathrm{O}$ system: First-principles calculations and a thermodynamic assessment. Geochim. Cosmochim. Acta 2013, 122, 398-417. DOI: $\underline{10.1016 / j . g c a .2013 .08 .028}$

Weber, J., Barthel, J., Brandt, F., Klinkenberg, M., Breuer, U., Kruth, M., Bosbach, D. Nanostructural features of barite crystals observed by electron microscopy and atom probe tomography. Chem. Geol. 2016, 424, 51-59. DOI: 10.1016/j.chemgeo.2016.01.018

Weigl, F., Trinkl, A., Crystal chemistry of radium, II, radium salts of the type $\mathrm{RaXO}_{4}, \mathrm{X}=\mathrm{S}$, Se, Cr, Mo, W, Radiochim. Acta, 1968, 9: 140-4.

Zhang, T., Gregory, K., Hammack, R. W., Vidic, R. D. Co-precipitation of Radium with Barium and Strontium Sulfate and Its Impact on the Fate of Radium during Treatment of Produced Water from Unconventional Gas Extraction. Environ. Sci. Technol. 2014, 48, 4596-4603. DOI: 10.1021/es405168b

Zhang, X., He, Y., Sushko, M.L., Liu, J., Luo, L., De Yoreo, J.J., Mao, S.X., Wang, C., Rosso, K. Direction-specific van der Waals attraction between rutile $\mathrm{TiO}_{2}$ nanocrystals. Science. 2017, 356, 6336, 434-437. DOI: 10.1126/science.aah6902 
697 Zhang, Y., Geochemical kinetics, Princeton University Press, 2008,.

698 Zhang, Y., Ni, H., Chen, Y., Diffusion data in silicate melts: Reviews in Mineralogy and 699 Geochemistry, 2010, v. 72, no. 1, p. 311-408.

700 